\title{
Article \\ Compensation of Voltage Sags and Swells Using Dynamic Voltage Restorer Based on Bi-Directional H-Bridge AC/AC Converter
}

\author{
Yu-Kai Chen ${ }^{1, *}$, Xian-Zhi Qiu ${ }^{2}$, Yung-Chun $W^{1}{ }^{1}$ and Chau-Chung Song ${ }^{1}$ \\ 1 Department of Aeronautical Engineering, National Formosa University, Hu-Wei 632, Taiwan; \\ ycwu@nfu.edu.tw (Y.-C.W.); ccsong@nfu.edu.tw (C.-C.S.) \\ 2 Fego Precision Industrial Co. Ltd., Taichung 413, Taiwan; chiu_hc@fego.com.tw \\ * Correspondence: ykchen@nfu.edu.tw
}

Citation: Chen, Y.-K.; Qiu, X.-Z.; Wu, Y.-C.; Song, C.-C. Compensation of Voltage Sags and Swells Using Dynamic Voltage Restorer Based on Bi-Directional H-Bridge AC/AC Converter. Processes 2021, 9, 1541. https://doi.org/10.3390/pr9091541

Academic Editors: Chang-Hua Lin and Jahangir Hossain

Received: 29 June 2021

Accepted: 24 August 2021

Published: 30 August 2021

Publisher's Note: MDPI stays neutral with regard to jurisdictional claims in published maps and institutional affiliations.

Copyright: (c) 2021 by the authors. Licensee MDPI, Basel, Switzerland. This article is an open access article distributed under the terms and conditions of the Creative Commons Attribution (CC BY) license (https:// creativecommons.org/licenses/by/ $4.0 /)$.

\begin{abstract}
In this paper, the compensation of voltage sags and swells using a dynamic voltage restorer (DVR) based on a bi-directional AC/AC converter is presented for stabilizing single-phase AC line voltage. The H-bridge AC/AC converter with bi-directional switches and without bulk capacitor is adopted as the power topology of the proposed system. The proposed novel topology of DVR is adopted to compensate both voltage sag and swell conditions. Additionally, the power factor is closed to unity because a bulk capacitor is not required. The inner and outer loop control is proposed to improve the response with gain scaling; gain control is adopted to reduce the overshoot. Finally, a $2 \mathrm{kVA}$ prototype has been implemented to verify the performance and accuracy of the control method for the DVR system. The peak efficiency of the system is up to $94 \%$, and it can compensate $50 \%$ voltage swells and $25 \%$ voltage sags.
\end{abstract}

Keywords: DVR; H-bridge; voltage sag; voltage swell

\section{Introduction}

Thanks to industrial automation, in recent years electronic facilities are increasingly demanding with respect to the quality of their electricity, such as sudden voltage sags/swells, and demand for an output voltage with low harmonic distortion. Sudden voltage sags (caused mainly by the starting of high-power motors or by short circuit) are normally the most common disruptions for electrical systems. They account for more than $90 \%$ of power quality issues. Voltage swell, on the other hand, occurs when switching large capacity devices, removing heavy loads, and when uni-directional ground connection malfunctions occur. Sudden voltage sags affect systems tremendously. Modern semiconductor facilities, such as computer communications systems, measurement instruments and production machineries, are all very sensitive to voltage changes. Even a mere three to five cycles of voltage change can hang systems and affect factory production. It follows, then, that since all of the high-tech industries use computerized, automated systems that are highly voltage sensitive, investment in stable voltage output and power quality is a required necessity.

As dynamic voltage restorers (DVRs) need to be highly efficient and highly reliable, their deployment requires both electrical and electronic techniques. There are two types of DVR systems: one uses the energy storage element to supply the compensated power source, as shown in Figure 1a, and the other uses the utility power source with AC/DC converter to supply the compensated power, as shown in Figure 1b. Figure 1c shows the proposed novel AC/AC converter used in this paper to compensate the power source for the DVR system without a bulk capacitor, in order to improve system efficiency and reduce the cost of the proposed DVR system with the proposed single-stage AC/AC converter. 


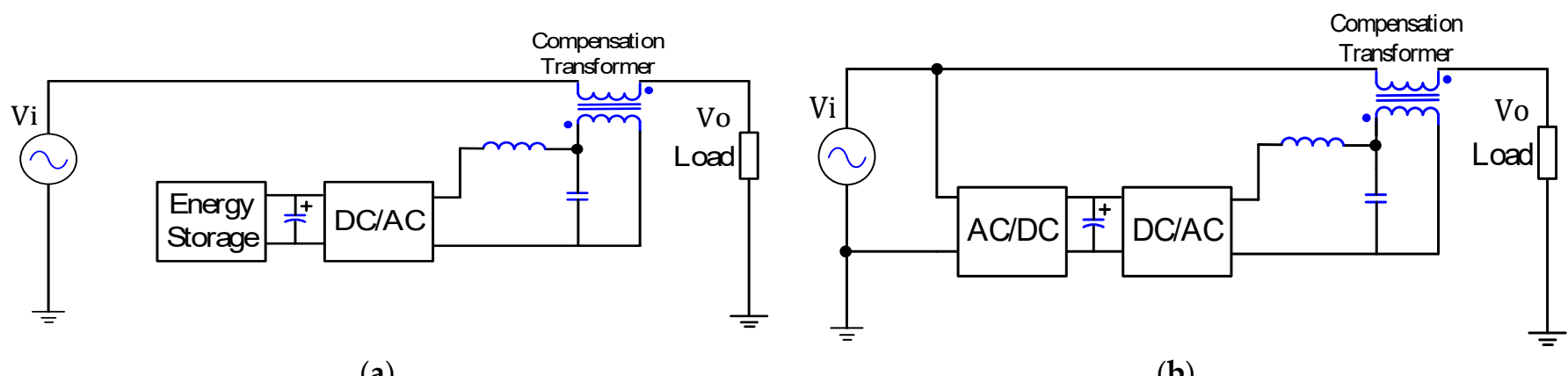

(a)

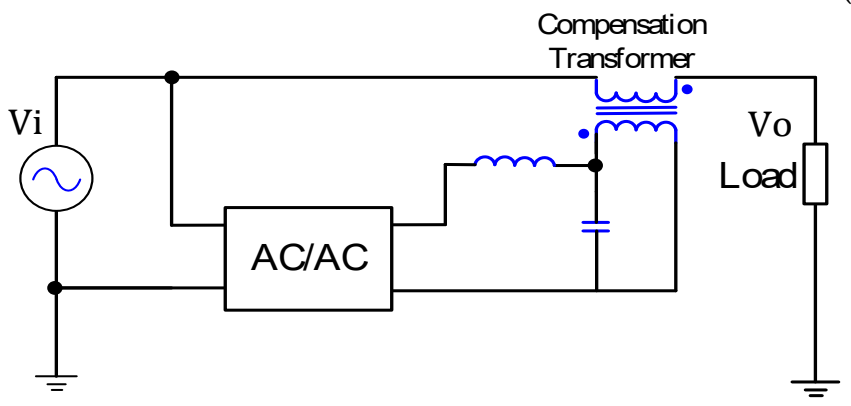

(c)

Figure 1. The types of DVR systems: (a) DC/AC, (b) AC/DC/AC, and (c) the proposed AC/AC.

Transformer-based regulations and inverter-based voltage regulators are the two main voltage regulation methods. Although the transformer-based regulator is widely adopted in electrical power systems, its dynamic response is limited by the slow movement of the taps or movable contacts. Inverter-based regulators use power electronics technology to regulate the output voltage. This type of method is implemented by H-bridge inverter and is suitable for applications requiring a sag voltage. The literature [1-3] presents the various characteristics of voltage sags and interruptions within industrial distribution systems and compensation methods for real power and reactive power. The DVR can be implemented at both a low voltage level and medium voltage level to protect high-power applications from voltage sags [4-6]. Some published literature proposes a DVR application system using transformer coupled H-bridge converters [7-9] to maintain the output voltage within the desired level when the system is operated in voltage sag. However, these applications [4-9] only aim to prevent voltage sag without voltage swell. Additionally, a cascaded H-bridge dynamic voltage restorer (CHB-DVR) is presented and discussed in [10] for the output compensation voltage that maximizes its output voltage level number. The research paper presented a DVR system with differential inverter topology [11]. There seems to be less research regarding dynamic voltage restorers, particularly discussing the implementation of $\mathrm{AC} / \mathrm{AC}$ converters. In this paper, the proposed $\mathrm{H}$-bridge $\mathrm{AC} / \mathrm{AC}$ converter with bi-directional switches can compensate for both sag and swell conditions.

The literature referred to in [12-16] discusses using Z-source and Quasi-Z-source converters to achieve dynamic voltage restoration. The $\mathrm{z}$-source network can produce the desired output voltage, which is greater or lesser than the line voltage. The Z-source network consists of two inductors and two capacitors connected in an X-shape. The Zsource with an L-C filter is needed to form an AC/AC converter and compensate the voltage sag and swell. Therefore, the z-source AC/AC converter of the DVR system has too many circuit components. The adaptive scheme for DVR to voltage sag compensation and energy self-recovery has been presented in [17]. The adaptive schemes improve the voltage quality of sensitive loads by protecting them during grid voltage sags with phase angle jump. 
This paper mainly aims to develop a novel AC/AC converter to resolve power grid voltage sag and swell, and with them the machinery malfunctions and crashes that they cause. This paper proposes a new bi-directional AC/AC converter of highly efficient, low-cost AC dynamic voltage restoration. It uses an inner-outer loop controller activated pulse width modulation method, which, coordinating with a bi-directional full-bridge converter, forms an AC/AC converter that can reverse voltage polarity. Then, it goes through a low-frequency transformer and a series connects input voltage to achieve voltage compensation and stable output voltage.

\section{Design of a Single-Phase DVR}

The design specifications of the proposed single-phase DVR system are shown in Table 1 . To achieve the required compensated output voltage that a DVR needs to quickly react to voltage changes, this research chose to implement a direct AC-to-AC conversion. The block diagram of the proposed system is shown in Figure 2. The proposed DVR includes the AC/AC converter, auxiliary power supply circuit, protection and feedback circuits, and the Renesas micro-controller. The AC-AC converter provides the required compensation for voltage swells and sags, and it is series-connected to the input voltage with a low-frequency transformer; the auxiliary power supply circuit provides the required power for the microprocessor and the driving circuit; the protection and feedback circuits are to allow feedback variables (such as the input voltage $V_{i}$, output voltage $V_{o}$, and the output current $\left.I_{\text {out }}\right)$ to execute compensation control and circuit protection functions; the Renesas micro-controller uses model M16/C29 for implementation. To solve the problems of voltage swell and sag, it was determined that the output voltage $V_{\text {out }}$ of the AC/AC converter needs to compensate by

$$
V_{o}=V_{\text {in }} \times G(D)
$$

where $V_{o}$ is the output voltage, $V_{i n}$ is the input voltage, $G(D)$ is the gain for the AC/AC converter, and $n$ is the low-frequency transformer's winding turn ratio. Equation (1) shows that when the voltage takes a sudden dip, the required voltage compensation $V_{\text {out }}$ must be positive, and when the voltage spikes, the required voltage compensation $V_{\text {out }}$ must be negative. This means that the AC/AC converter's gain $G(D)$ must have the ability to be both positive and negative. Because the range of duty ratio $D$ is between 0 and 1 , this research used a divisive Equation (2) to enable the positive/negative possibility:

$G(D)$ is positive, if $D>0.5$,

$G(D)$ is negative, if $D<0.5$

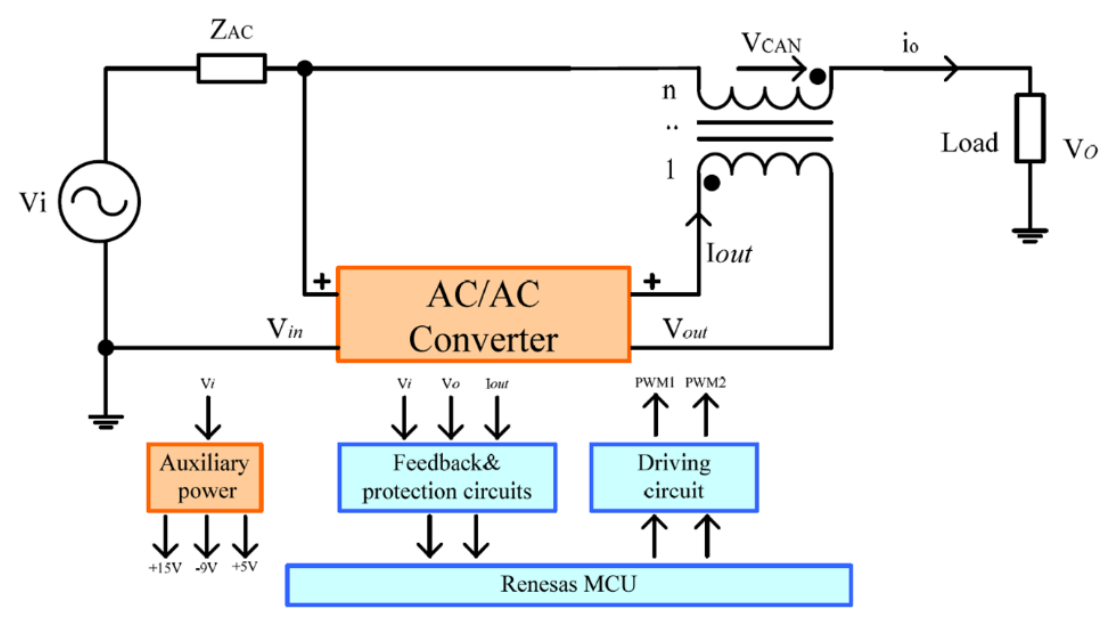

Figure 2. The system block diagram of DVR. 
Table 1. The design specifications of DVR.

\begin{tabular}{ll}
\hline Parameters & Values \\
\hline Output voltage & $220 \mathrm{Vrms}$ \\
Rated power & $2 \mathrm{kVA}$ \\
Input voltage variation & $-50 \% \sim+25 \%$ \\
Series transformer turns ratio & $1: 1.2$ \\
Response & $<4 \mathrm{~ms}$ \\
Output regulation & $<3 \%$ \\
\hline
\end{tabular}

\subsection{Bi-Directional H-Bridge Topology}

The method and principle behind the AC converter design shown in Figure 3 may be understood via the description above. When the output voltage dips, the converter must provide positive voltage to compensate for the voltage missing, so here the AC chopper is to provide energy. When the output voltage spikes, the converter must provide negative voltage to compensate for the voltage overage, so here the AC chopper must accept energy. Therefore, the AC converter must not only be able to produce positive and negative voltages, it needs to provide two-way functionality in order to fulfil compensation needs. This research used a full-bridge converter as the framework for the AC converter, and it used the sequentially activated pulse width modulation method to implement circuit switch control, achieving voltage compensation and stabilization functionality. The circuit diagram, as shown below, uses 4 sets of switches $\left(\mathrm{M}_{1} \sim \mathrm{M}_{4}\right)$ to complete the full-bridge circuitry. Each set of switches uses two IGBT pieces, connected back to back, then goes through the filter circuit composed of inducers and capacitors, completing the AC converter circuit design. The filter inductance and capacitance inductance were selected as $1.5 \mathrm{mH}$ and $2 \mu \mathrm{F}$, respectively. The inductor was made up of MPP (molybdenum permalloy, $\mathrm{Ni}-\mathrm{Fe}-$ Mo powder core), and the model was CM778060. The capacitor of the filter used the MEF (Metallized Polyester Film) series, using two $1 \mu \mathrm{F}$ capacitors in parallel.

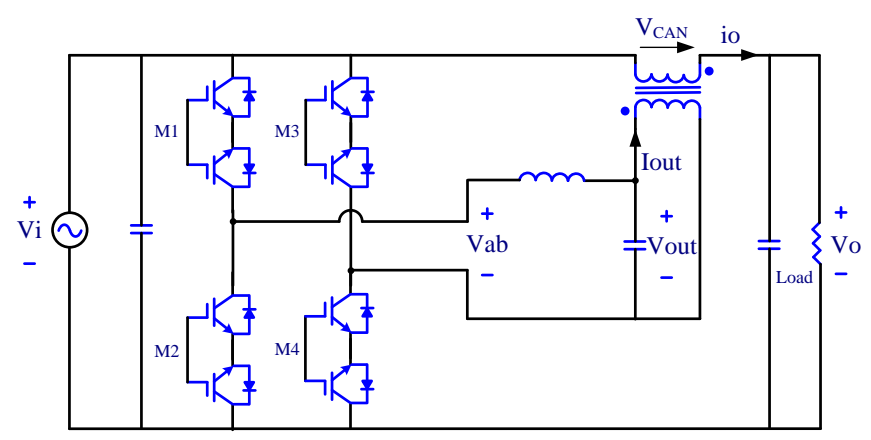

Figure 3. The circuit diagram of the single-phase DVR.

\subsection{Circuit Action Principle}

The AC/AC converter acts under two modes and four conditions: when power from the grid enters at a voltage lower than the set value, the condition is called a voltage sag mode, which operates in mode 1; when power from the grid comes in at higher than another set voltage, the condition is called a voltage swell mode, which operates in mode 2. In a single cycle, mode 1 and mode 2 may have four conditions.

\subsubsection{Mode 1, Voltage Sag Mode}

This mode, when operating, provides power from the input terminal $V_{i}$ to the output terminal $V_{\text {out }}$. Below are the principles of action for the various modes, as shown in Figure 4 . 
Mode 1-1: As shown in Figure 4a, while in this mode switches $\mathrm{M}_{1}$ and $\mathrm{M}_{4}$ are open, guiding the input voltage through the $\mathrm{M}_{1}, \mathrm{M}_{4}$ pathway, charging the inducer magnetically and the capacitor with electricity. At this point the inducer's voltage is $V_{i}-V_{\text {out }}$.

Mode 1-2: As shown in Figure $4 b$, while in this mode switches $M_{2}$ and $M_{4}$ are open, providing a path for the inducer's current flow and charging the capacitor's charge load. At this point the inducer's voltage is $-V_{\text {out }}$.

Mode 1-3: As shown in Figure 4c, this mode is the same as Mode 1-1. Switches $\mathrm{M}_{1}$ and $\mathrm{M}_{4}$ guide the input voltage through the $\mathrm{M}_{1}, \mathrm{M}_{4}$ pathway, charging the inducer magnetically and the capacitor with electricity. At this point the inducer's voltage is $V_{i}-V_{\text {out }}$.

Mode 1-4: As shown in Figure $4 d$, this mode is the same as Mode 1-3. Switches $M_{1}$ and $\mathrm{M}_{3}$ are open, providing a path for the inducer's current flow, charging the capacitor's charge load. At this point the inducer's voltage is $-V_{\text {out }}$.

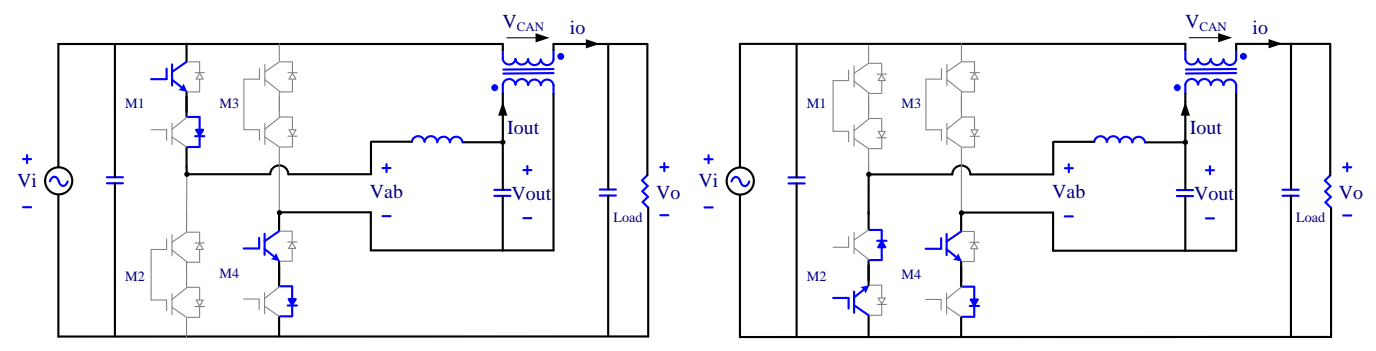

(a)

(b)

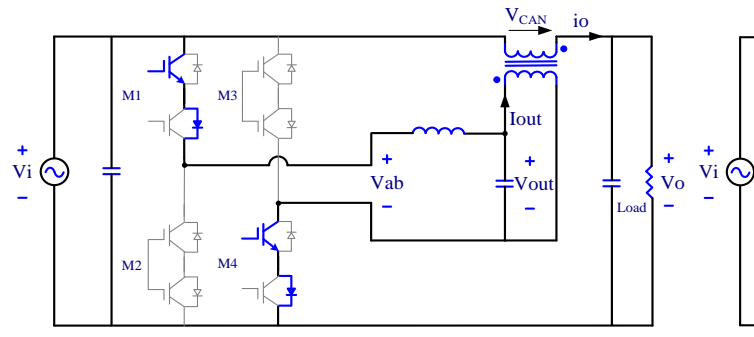

(c)

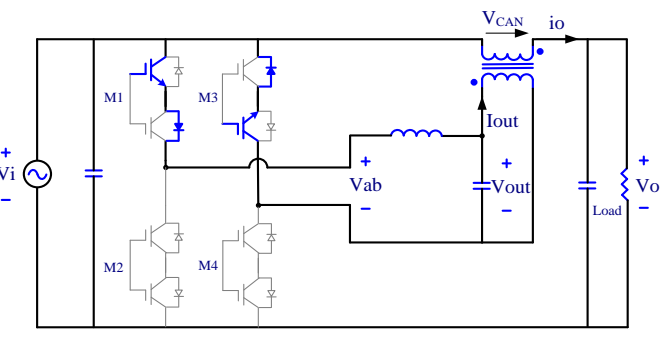

(d)

Figure 4. Operating principle: (a) Mode 1-1, (b) Mode 1-2, (c) Mode 1-3, and (d) Mode 1-4.

\subsubsection{Mode 2, Voltage Swell Mode}

This mode sends power from output terminal $V_{\text {out }}$ back to the input terminal $V_{i}$. Below are the actional principles for the various modes, as shown in Figure 5.

Mode 2-1: While in this mode switches $\mathrm{M}_{2}$ and $\mathrm{M}_{4}$ are open, and output voltage goes through the $\mathrm{M}_{2}, \mathrm{M}_{4}$ pathway, charging the inducer magnetically. At this time the inducer's voltage is $-V_{\text {out }}$.

Mode 2-2: While in this mode switches $\mathrm{M}_{2}$ and $\mathrm{M}_{3}$ are open; the inducer's current flows through the $\mathrm{M}_{2}, \mathrm{M}_{3}$ pathway and provides power to input $V_{i}$. At this point the inducer's voltage is $-V_{\text {out }}-V_{i}$.

Mode 2-3: This mode is similar to Mode 2-1. Switches $M_{1}$ and $M_{3}$ are open, and output voltage flows through the $\mathrm{M}_{2}, \mathrm{M}_{4}$ pathway, charging the inducer magnetically. At this time the inducer's voltage is $-V_{\text {out }}$.

Mode 2-4: This mode is the same as Mode 2-2. Switches $\mathrm{M}_{2}$ and $\mathrm{M}_{3}$ are open, and the inducer current flows through the $\mathrm{M}_{2}, \mathrm{M}_{3}$ pathway, sending energy back to $V_{i}$. At this time the inducer's voltage is $-V_{\text {out }}-V_{i}$. 


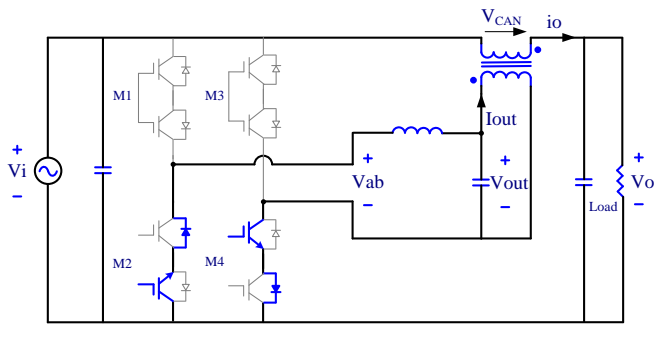

(a)

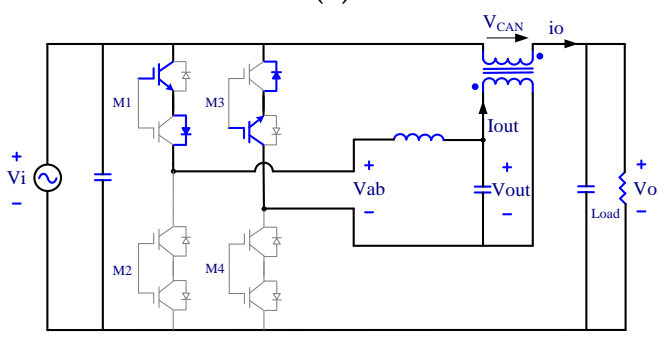

(c)

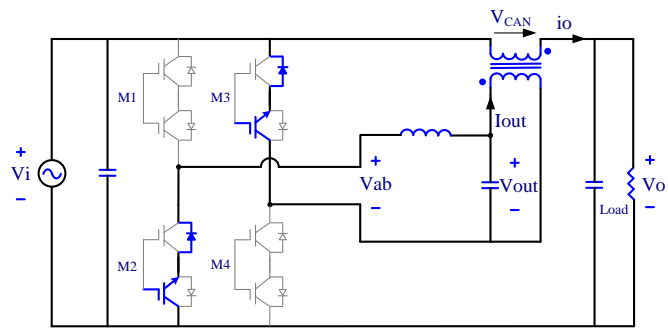

(b)

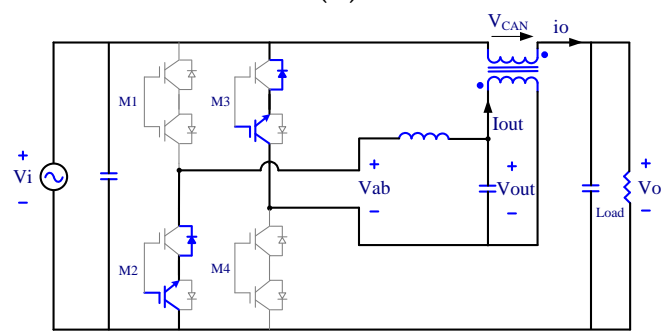

(d)

Figure 5. Voltage Overage Mode circuit action principle: (a) Mode 2-1, (b) Mode 2-2, (c) Mode 2-3, and (d) Mode 2-4.

\subsection{System Gain and Control}

The AC converter, when operating under Mode 1 , is in Buck Mode, and the input $V_{i}$ provides power to the output $V_{\text {out }}$. However, when under Mode 2 it is in Boost Mode, and the output $V_{\text {out }}$ sends energy back to input $V_{i}$. Thus, the AC converter can be considered to operate under two modes: buck and boost. The converter's duty is determined by the ratio of each cycle's inducer magnetization; this research used a sequential activation method for control, giving each cycle 4 conditions during operation. When operating in Buck Mode, in each cycle there are two instances of inductance magnetization, in Mode 1-1 and Mode 1-3 respectively. Thus, when in buck mode the duty is determined by the connection (activation) time of $\mathrm{M}_{1}$ and $\mathrm{M}_{4}$. However, in Boost mode there are also two instances of inductance magnetization, respectively in Mode 2-1 and Mode 2-3. When in Mode 2-1, the Duty is determined by $\mathrm{M}_{2}$ and $\mathrm{M}_{4}$, and when in Mode 2-3 the Duty is determined by $\mathrm{M}_{1}$ and $\mathrm{M}_{3}$. To simplify control, $\mathrm{M}_{1}$ will be solely used for system Duty, and the conversion process is as below.

Boost (Mode 2) voltage gain is $V_{i} / V_{\text {out }}=1 /(1-\mathrm{D})$. Because input $V_{i}$ and output $V_{\text {out }}$ are opposite to Buck (Mode 1 ), one can change the formula to $V_{\text {out }} / V_{i}=1-\mathrm{D}$. Since the system duty is mainly Buck (Mode 1), the size of the duty is determined by the ratio taken by the 1 connection. However, the Boost magnetization mode is very different from its Buck counterpart and is directly opposite. Thus, we combine these two modes and obtain $V_{\text {out }} / V_{i}=2(\mathrm{D}-0.5)$, as shown in the line graph in Figure 6 where gain is the ratio between the output voltage and the input voltage. The time sequence diagram is as shown in Figure 7, where $\mathrm{M}_{1} \sim \mathrm{M}_{4}$ are the switch control waves, Vab is the full-bridge output wave, and $V_{\text {out }}$ is the AC converter's output voltage.

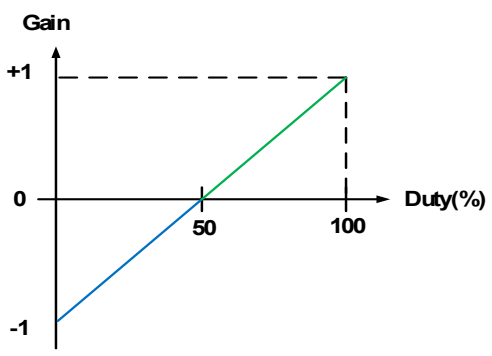

Figure 6. The gain curve vs. duty ratio for bi-directional H-bridge AC/AC converter. 


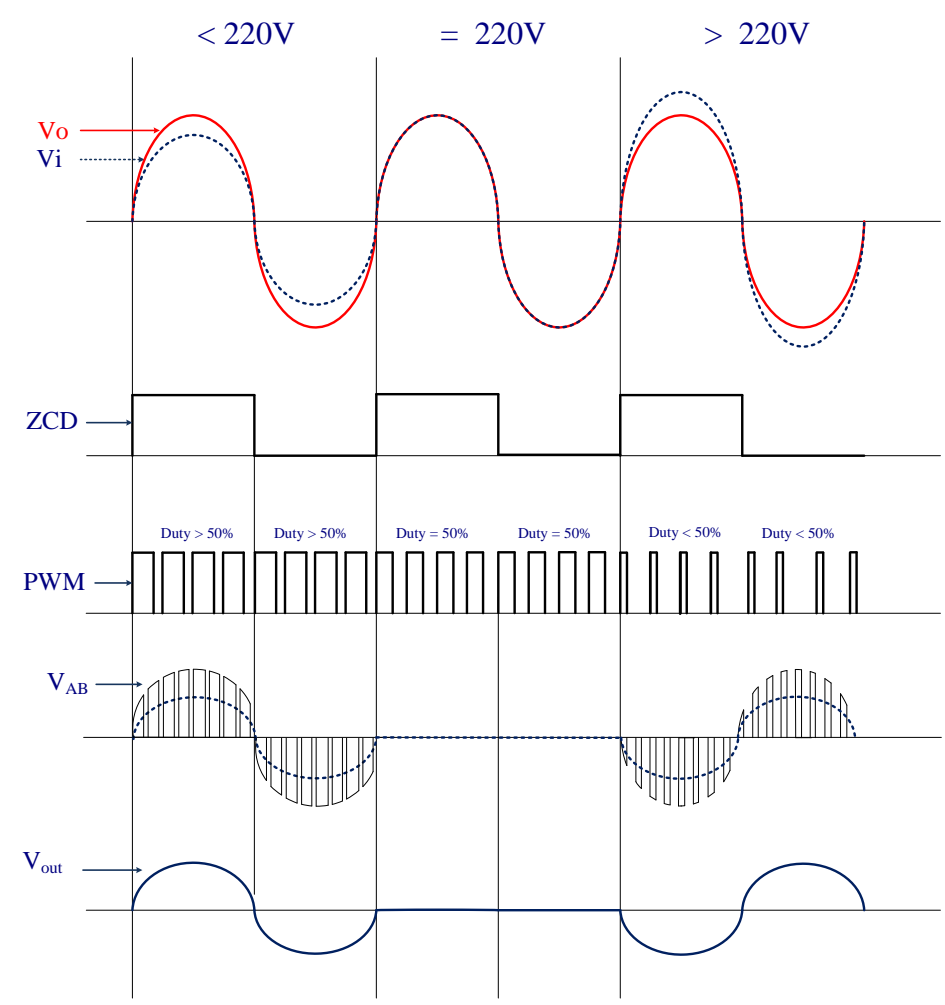

Figure 7. The key waveforms of the H-bridge AC/AC converter.

The system control block diagram is shown in Figure 8. The inner-outer loop control of the proposed DVR system is adopted to improve the system response. The output voltage and output current variables are controlled by the outer and inner loops, respectively. However, the gain scaling control is adopted to reduce the overshoot of the system when the DVR is operated in the transient state. For example, the PI and P controllers are adopted in the inner-outer loop control to compensate the output voltage when the system is operated in voltage sag mode. However, if the DVR system suddenly changes to normal mode from voltage sag mode, overshoot will occur as shown in the red dashed area of Figure 9. The overshoot is an important issue in that the output voltage is at maximum when the transient mode of the DVR system occurs at the peak of a line positive half-cycle or negative half-cycle.

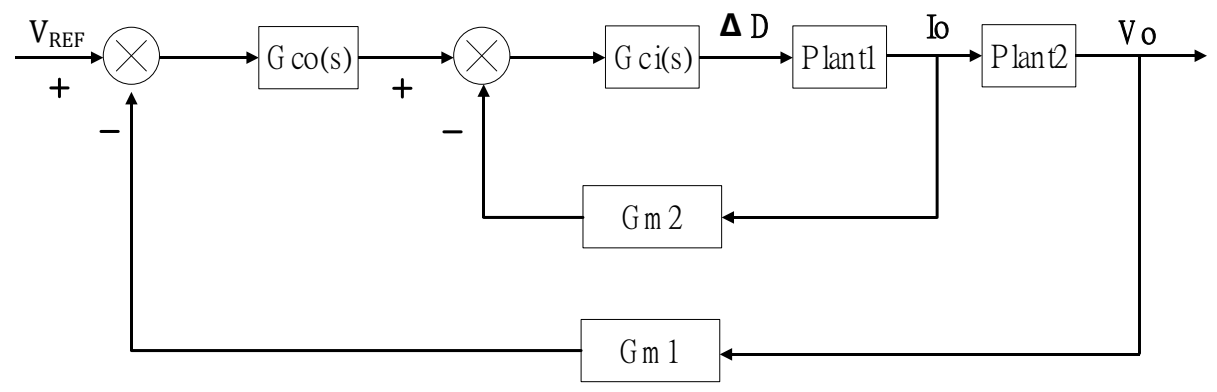

Figure 8. The system control block diagram.

The design procedures of inner-outer loop controllers are listed as follows:

Step 1: Design a proportional (P) controller of inner loop with output current feedback

$$
G_{c i}(s)=K_{P}
$$


Step 2: Design a proportional-integral (PI) controller of inner loop with output voltage feedback

$$
G_{c o}(s)=K_{P}+\frac{K_{i}}{s}
$$

Step 3: Determine the modified duty ratio $D_{N}$

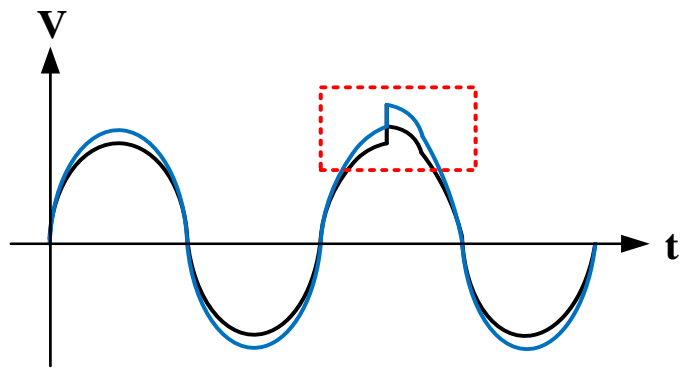

(a)

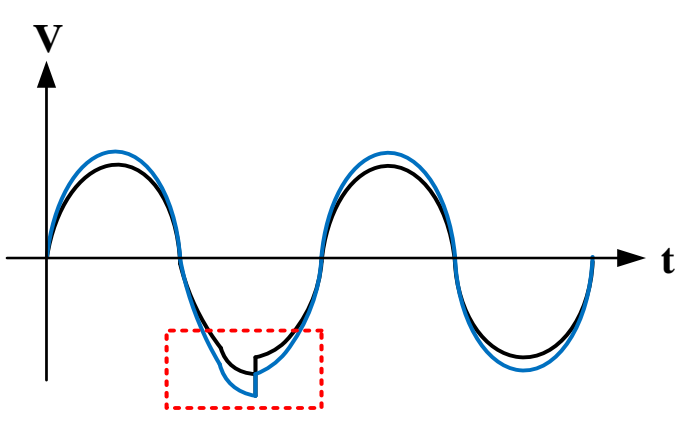

(b)

Figure 9. The output voltage waveform when the system is operated in voltage sag to normal modes: (a) positive half-cycle and (b) negative half-cycle.

From the above step 1 and step 2, we can derive the duty ratio $D_{O}$ of the H-bridge. To improve the system response and reduce the system overshoot, the modified duty ratio is derived based on the below gain scaling rule.

If $\left|V_{o}-V_{r e f}\right| \leq V_{r e f} \times 5 \%$, then $D_{N}=D_{o}$. Else $D_{N}=D_{o}+D_{M}$, where $D_{M}$ is variation of duty ratio.

The duty ratio $\mathrm{D}$ of the proposed $\mathrm{H}$-bridge will be adjusted when the output voltage is not operated in the blue-dashed area $\left(\left|V_{o}-V_{\text {ref }}\right| \leq V_{\text {ref }} \times 5 \%\right)$ of Figure 10 . There are 6 regions of the line cycle; the modified variation of duty ratio $D_{M}$ is determined as follows:

Region 1: If $\theta<15^{\circ}$ or $165^{\circ}<\theta<180^{\circ}$, then $D_{M}=1 \%$,

Region 2: If $15^{\circ}<\theta<30^{\circ}$ or $150^{\circ}<\theta<165^{\circ}$, then $D_{M}=1.5 \%$,

Region 3: If $30^{\circ}<\theta<45^{\circ}$ or $135^{\circ}<\theta<150^{\circ}$, then $D_{M}=2 \%$,

Region 4: If $45^{\circ}<\theta<60^{\circ}$ or $120^{\circ}<\theta<135^{\circ}$, then $D_{M}=2.5 \%$,

Region 5: If $60^{\circ}<\theta<75^{\circ}$ or $105^{\circ}<\theta<120^{\circ}$, then $D_{M}=3 \%$,

Region 6: If $75^{\circ}<\theta<105^{\circ}$, then $D_{M}=3.5 \%$,

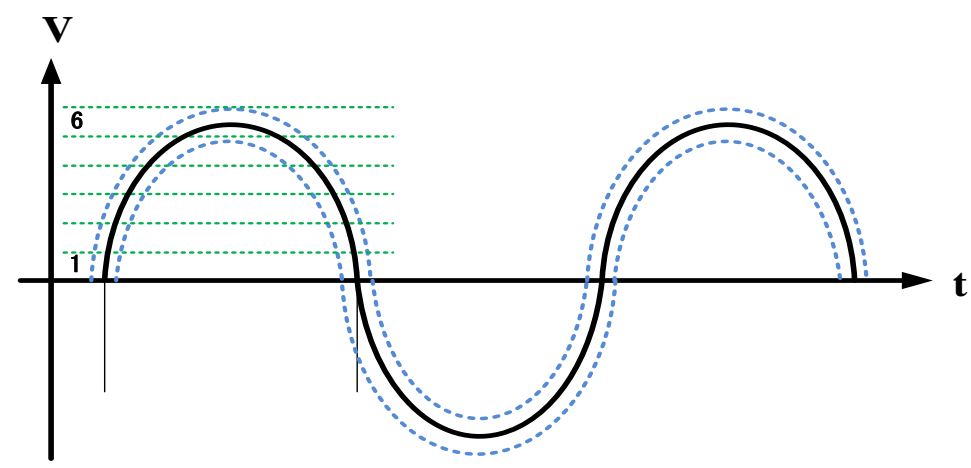

Figure 10. Gain scaling control principle.

\section{Simulation and Experiment Results}

\subsection{Simulation Results}

To design the low-frequency transformer's turn ratios, we considered the range within which voltage swells and voltage sags occur. If the voltage sag range is set to $50 \%$ and the voltage swell range set to $25 \%$, then the winding ratio would be $1: 1.2$ in this paper. Figure $11 \mathrm{a}, \mathrm{b}$ shows the simulated waveforms when the DVR is operated under a $50 \%$ 
voltage sag and when it is operated under a $25 \%$ voltage swell, respectively. In order, the waveforms are for input voltage $V_{i}$, output voltage $V_{o}$ and AC/AC output voltage $V_{\text {out }}$. We can see that from the simulated results, the compensation effect instantly compensated for the input voltage change.

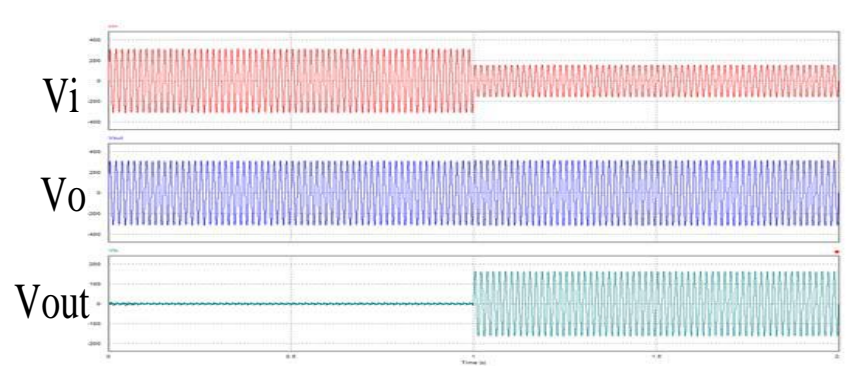

(a)

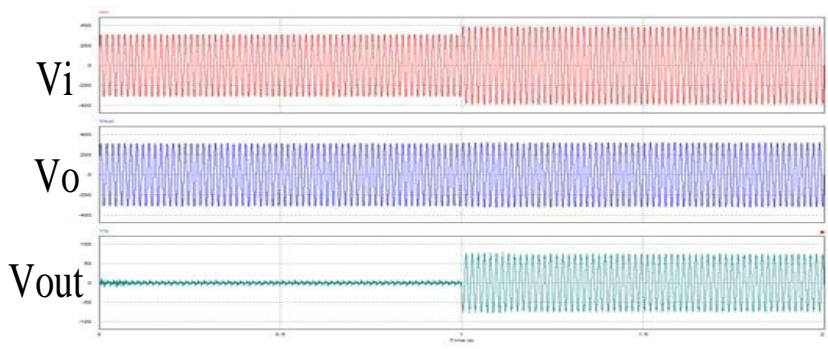

(b)

Figure 11. The simulated waveforms when the system is operated in (a) voltage sag, (b) voltage swell.

\subsection{Steady-State Performance of Experimental Results}

The experimental results in Figure $12 \mathrm{a}-\mathrm{c}$ show the proposed DVR system with a PI controller when the system is operated in voltage swell $\left(V_{i}=267 \mathrm{~V}\right)$, normal $\left(V_{i}=217 \mathrm{~V}\right)$, and swell $\left(V_{i}=127 \mathrm{~V}\right)$, respectively. From Figure 12 (the steady-state error of the DVR system with the proposed control method), the steady-state error can reach $0.0045 \%, 0.7 \%$, and $0.12 \%$, respectively.

Additionally, the simulated steady-state error of the proposed system under the same conditions as the experiment can reach $0.002 \%, 0.0015 \%$, and $0.0018 \%$, respectively. Therefore, the simulated results of the proposed system are better than measured results because there is no noise that affects the control effect.

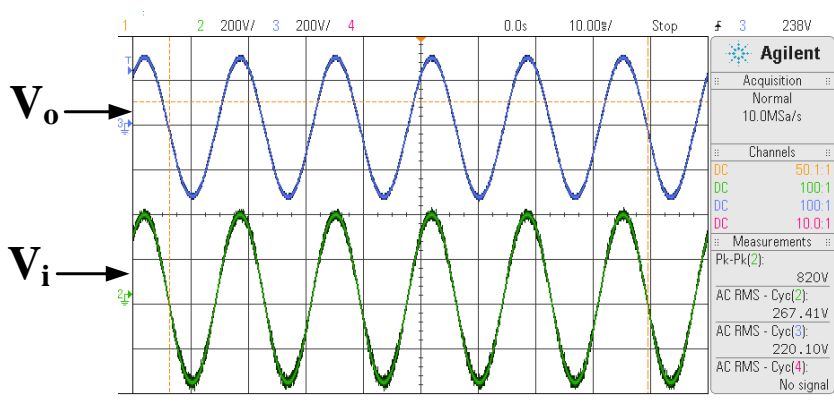

(a) $\left(V_{o}: 200 \mathrm{~V} /\right.$ div, $V_{i:} 200 \mathrm{~V} /$ div, Time: $\left.20 \mathrm{~ms}\right)$

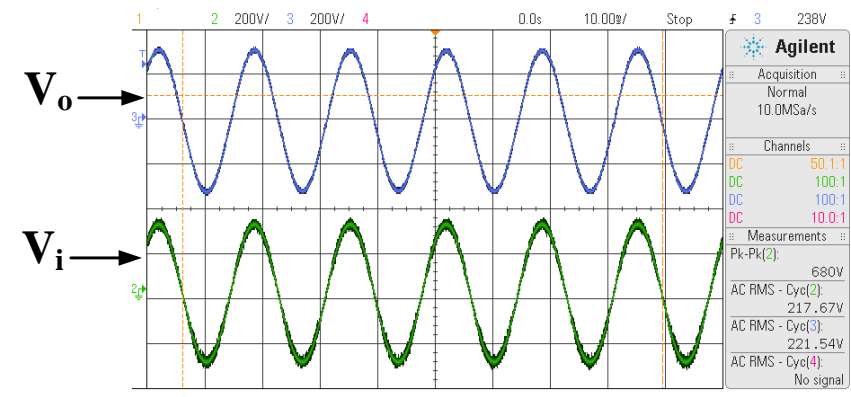

(b) $\left(V_{o}: 200 \mathrm{~V} /\right.$ div, $V_{i}: 200 \mathrm{~V} / \mathrm{div}$, Time: $\left.20 \mathrm{~ms}\right)$

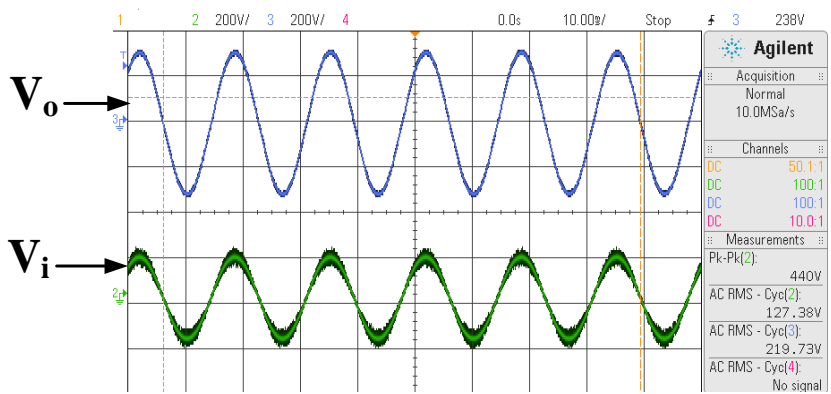

(c) $\left(V_{o}: 200 \mathrm{~V} /\right.$ div, $V_{i:} 200 \mathrm{~V} /$ div, Time: $\left.20 \mathrm{~ms}\right)$

Figure 12. The measured waveforms of the system when the input voltage is (a) $267 \mathrm{~V}$, (b) $217 \mathrm{~V}$, and (c) $127 \mathrm{~V}$.

\subsection{Dynamic Performance of Experimental Results}

Figure 13a shows the voltage from 220 Vrms suddenly dipping to 140 Vrms. Figure $13 \mathrm{~b}$ shows the voltage from 220 Vrms changing to 275 Vrms. The experimental result verified that the system indeed compensated for $25 \%$ over voltages and $50 \%$ under voltages within $4 \mathrm{~ms}$. Figure $13 \mathrm{c}$ is a waveform for power from the grid, originally at $220 \mathrm{~V}$, dipping 
suddenly to 140 Vrms and returning to $220 \mathrm{~V}$. Experimental results verified that the system does indeed provide voltage stabilization functionality. Figure $14 a, b$ shows the output voltage waveforms of the proposed DVR system, which is operated in the same region 6 of Figure 10, without a gain scaling controller and with one, respectively. From the figure, we can see that the overshoot will be reduced with the gain scaling controller. Figure 15 shows the efficiency of the proposed system when the input voltage varied from $140 \mathrm{Vrms}$ to $275 \mathrm{Vrms}$. From Figure 15 we can see that when the system is operated at $V_{i}=220 \mathrm{Vrms}$ no compensation voltage is needed at this time, because the input and regulated output voltages are the same, and no AC/AC converter is needed. Therefore, when the system is operated at $220 \mathrm{Vrms}$ and $360 \mathrm{~W}$, the peak efficiency is as high as $97 \%$. Another operating condition is when the input voltage $V_{i}=140 \mathrm{Vrms}$, the regulated output voltage difference of $80 \mathrm{~V}$ needs to be compensated. The compensation voltage of $80 \mathrm{Vrms}$ is obtained through the $\mathrm{AC} / \mathrm{AC}$ converter, and the output voltage is regulated at $220 \mathrm{Vrms}$ after the voltage series connection, so its efficiency is low. Figure 16 shows the measured power factor of the bi-directional switch AC/AC converter applied to the DVR with the proposed control method. The average input power factor of the bi-directional AC/AC converter is close to unity because the bulk capacitor of the topology is not required. Figure 17 shows the photograph of a $2 \mathrm{kVA}$ DVR prototype. The length, width and height of the system are $400 \mathrm{~mm}, 430 \mathrm{~mm}$, and $720 \mathrm{~mm}$, respectively. Figure 18 shows the proposed $9 \mathrm{kVA}$ three-phase DVR operated in voltage sag (input voltage $=168 \mathrm{~V}$ ) and voltage swell (input voltage $=252 \mathrm{~V}$ ). From the measured results, we can see that the proposed three-phase DVR system can maintain the output voltage within acceptable levels.

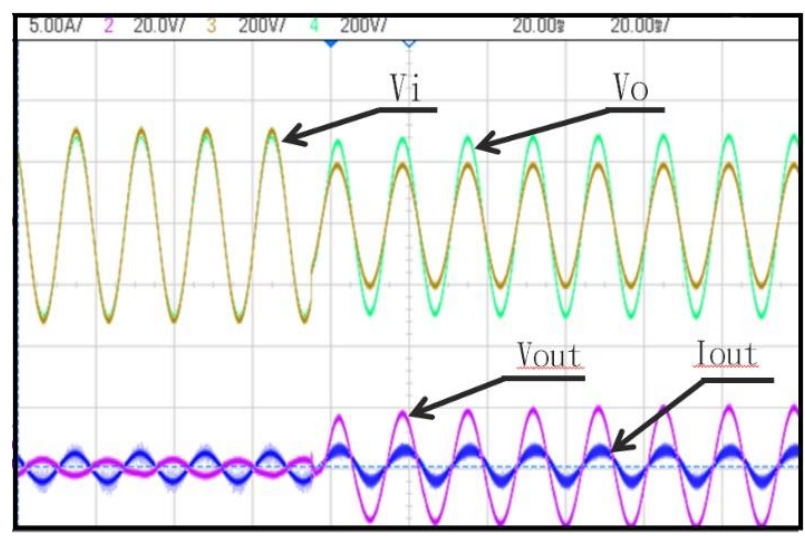

(a) (Iout $(\mathrm{CH} 1): 5 \mathrm{~A} / \mathrm{div}, V_{\text {out }}(\mathrm{CH} 2): 20 \mathrm{~V} / \mathrm{div}, V_{i}(\mathrm{CH} 3): 200 \mathrm{~V} / \mathrm{div}$, $V_{o}(\mathrm{CH} 4): 200 \mathrm{~V} / \mathrm{div}$, Time: $\left.20 \mathrm{~ms} / \mathrm{div}\right)$

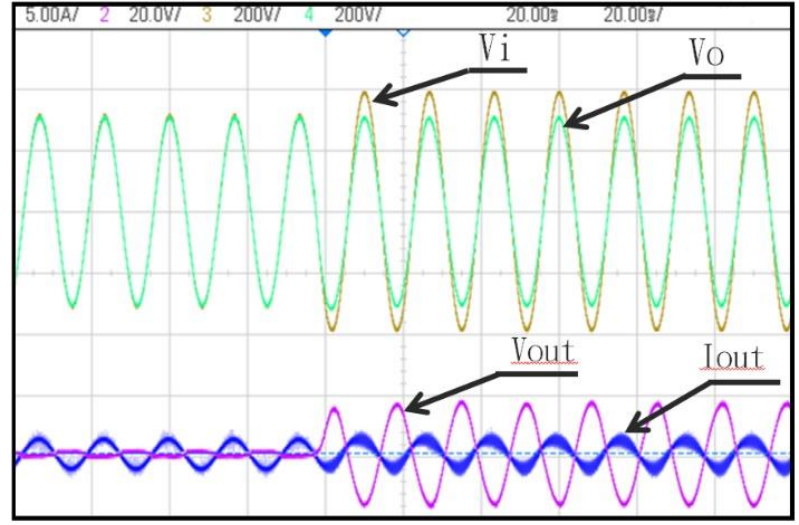

(b) (Iout $(\mathrm{CH} 1): 5 \mathrm{~A} / \mathrm{div}, V_{\text {out }}(\mathrm{CH} 2): 20 \mathrm{~V} / \mathrm{div}, V_{i}(\mathrm{CH} 3): 200 \mathrm{~V} / \mathrm{div}$, $V_{o}(\mathrm{CH} 4): 200 \mathrm{~V} / \mathrm{div}$, Time: $\left.20 \mathrm{~ms} / \mathrm{div}\right)$

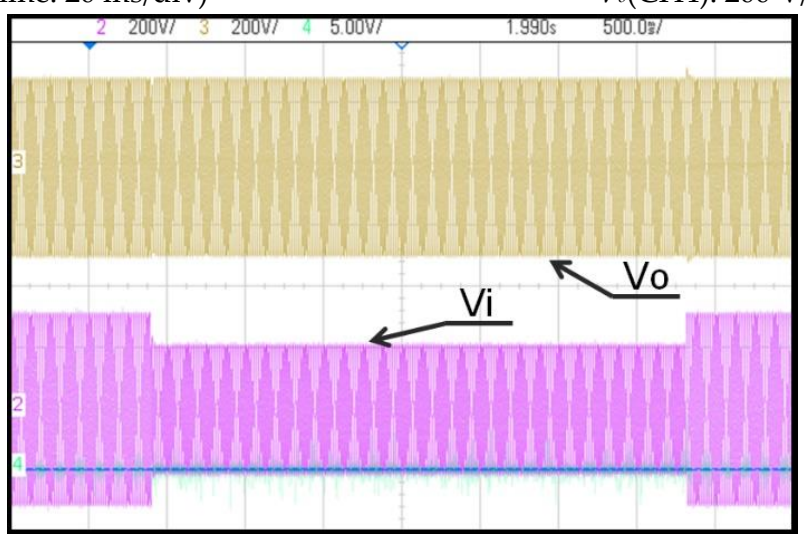

(c) $\left(V_{o}(\mathrm{CH} 2): 200 \mathrm{~V} / \mathrm{div}, V_{i}(\mathrm{CH} 3): 200 \mathrm{~V} / \mathrm{div}\right.$, Time: $\left.500 \mathrm{~ms} / \mathrm{div}\right)$

Figure 13. The measured waveforms of the system when operated in (a) voltage sag, (b) voltage swell, and (c) from voltage sag to normal. 


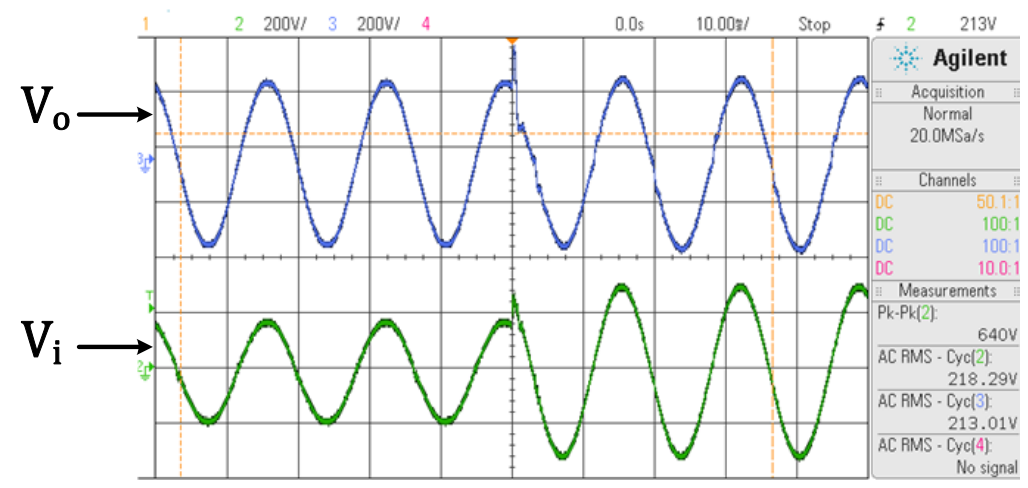

(a) $\left(V_{o}: 200 \mathrm{~V} /\right.$ div, $V_{i}: 200 \mathrm{~V} /$ div, Time: $\left.10 \mathrm{~ms}\right)$

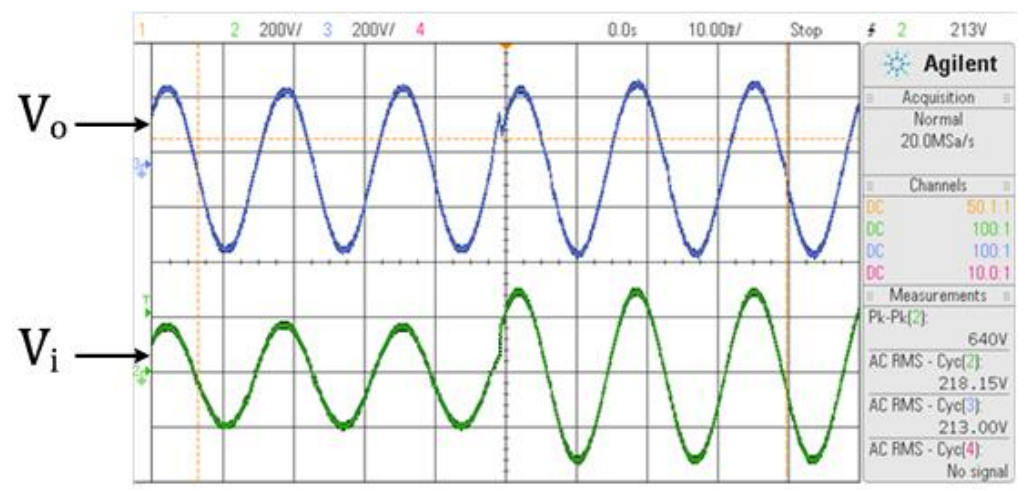

(b) $\left(V_{o}: 200 \mathrm{~V} / \mathrm{div}, V_{i}: 200 \mathrm{~V} / \mathrm{div}\right.$, Time: $\left.10 \mathrm{~ms}\right)$

Figure 14. The output voltage waveform of the proposed DVR (a) without gain scaling control and (b) with gain scaling control.

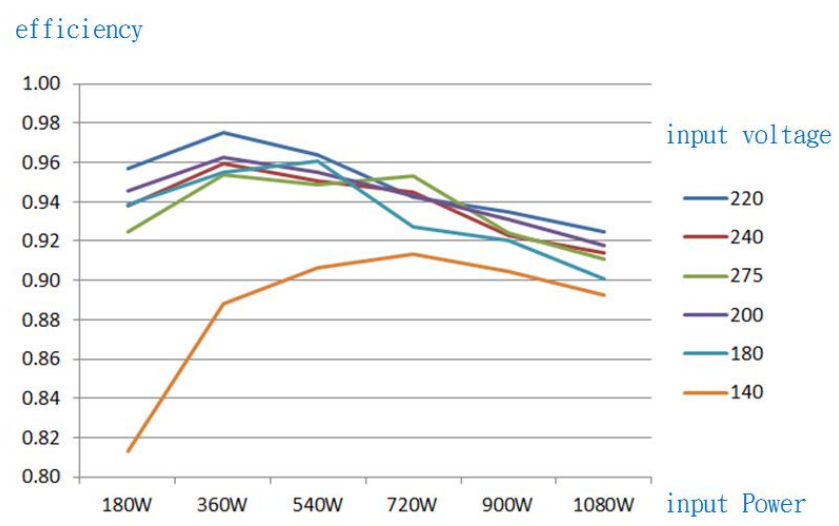

Figure 15. Output power vs. efficiency curve.

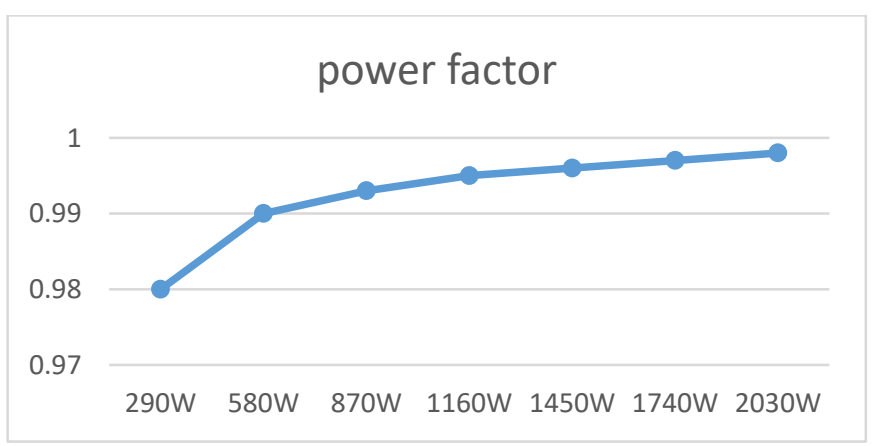

Figure 16. Output power vs. power factor curve. 


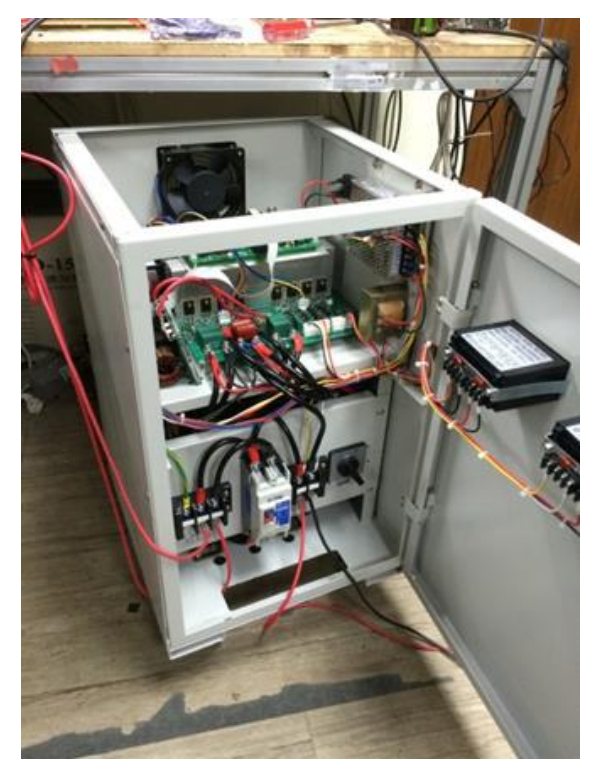

Figure 17. Photograph of a $2 \mathrm{kVA}$ DVR prototype.

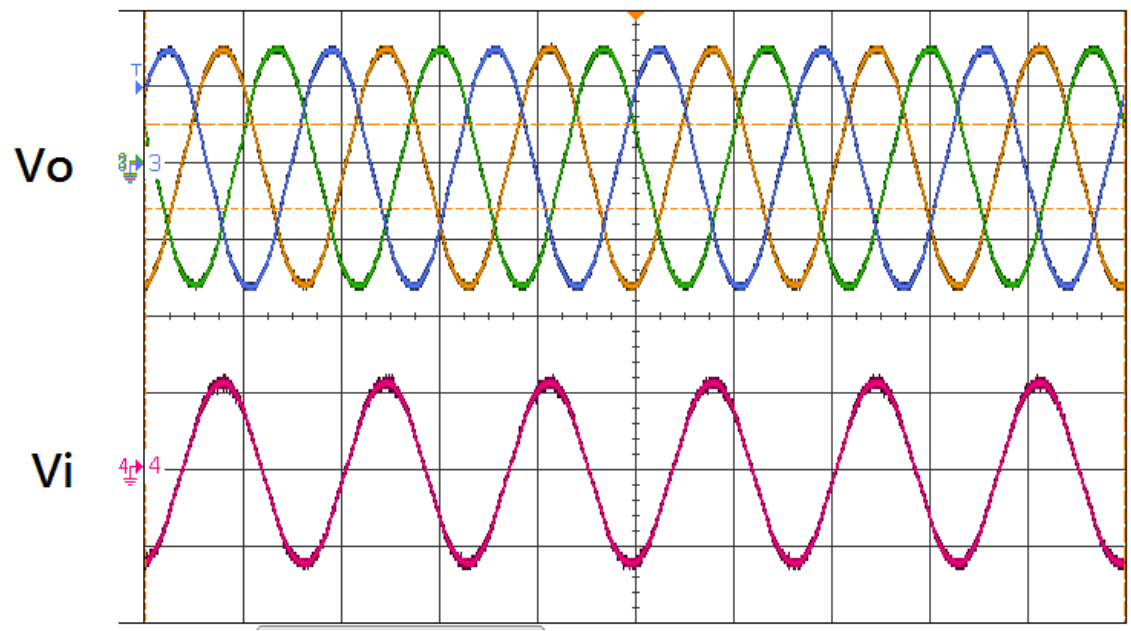

(a) $\left(V_{o}: 200 \mathrm{~V} / \mathrm{div}, V_{i}: 200 \mathrm{~V} / \mathrm{div}\right.$, Time: $\left.10 \mathrm{~ms}\right)$

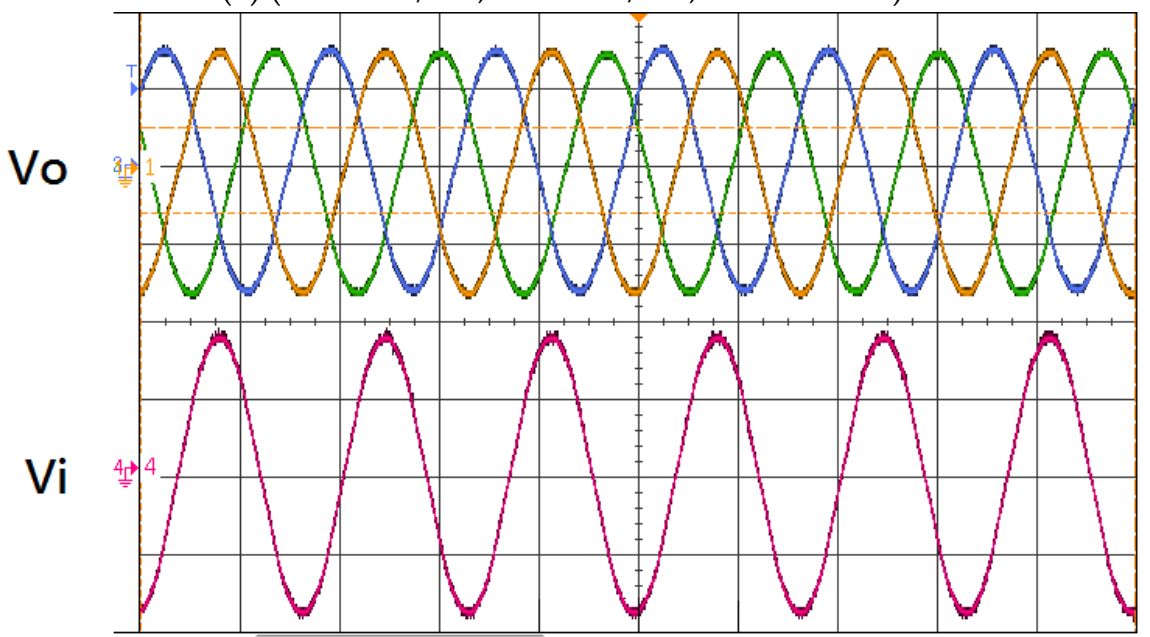

(b) $\left(V_{o}: 200 \mathrm{~V} /\right.$ div, $V_{i}: 200 \mathrm{~V} / \mathrm{div}$, Time: $\left.10 \mathrm{~ms}\right)$

Figure 18. The measured waveforms of the three-phase DVR system when operated in (a) voltage sag, (b) voltage swell. 


\section{Conclusions}

The H-bridge bi-directional AC/AC converter with inner-outer loop and gain scaling controls is presented for the proposed DVR system. A $2 \mathrm{kVA}$ prototype has been experimentally implemented and tested to verify the characteristics of the proposed DVR system when the system is operated in voltage sag and voltage swell. The simulation and experimental result shows that the proposed DVR system is proven to compensate the output voltage within $1 / 4$ cycle's time of power line, when subjected to utility power that has voltage sags and swells in the range of $-50 \%$ to $+25 \%$. The averaged efficiency of the DVR is close to $93 \%$ and P.F. is close to unity. This novel bi-directional AC/AC converter of DVR system has fast response, high efficiency and a high power factor.

Author Contributions: Y.-K.C., X.-Z.Q., and Y.-C.W. conceived the presented idea, designed, experimented and wrote this article; Y.-K.C. and C.-C.S. supervised the findings of this work. All authors have read and agreed to the published version of the manuscript.

Funding: This research was funded by the Ministry of Science and Technology, Taiwan, R.O.C., grant number MOST 110-2221-E-150-008 and MOST 110-2622-8-005-005-TE1.

Institutional Review Board Statement: Not applicable.

Informed Consent Statement: Not applicable.

Data Availability Statement: Not applicable.

Conflicts of Interest: The authors declare no conflict of interest.

\section{References}

1. Arrillaga, J.; Watson, N.R.; Chen, S. Power System Quality Assessment; Wiley: West Sussex, UK, 2000.

2. Bollen, M.H.J. Understanding Power Quality Problems: Voltage Sags and Interruptions; IEEE Press: New York, NY, USA, 1999.

3. Brumsickle, W.E.; Schneider, R.S.; Luckjiff, G.A.; Divan, D.M.; McGranaghan, M.F. Dynamic sag correctors: Cost-effective industrial power line conditioning. IEEE Trans. Ind. Appl. 2001, 37, 212-217. [CrossRef]

4. Woodley, N.H.; Morgan, L.; Sundaram, A. Experience with an inverter-based dynamic voltage restorer. IEEE Trans. Power Deliv. 1999, 14, 1181. [CrossRef]

5. Nielsen, J.G.; Newman, M.; Nielsen, H.; Blaabjerg, F. Control and testing of a dynamic voltage restorer (DVR) at medium voltage level. IEEE Trans. Power Electron. 2004, 19, 806-813. [CrossRef]

6. Boonchiam, P.; Mithulananthan, N. Dynamic control strategy in medium voltage DVR for mitigating voltage sags/swells. In Proceedings of the 2006 International Conference on Power System Technology, Chongqing, China, 22-26 October 2006; pp. 1-5.

7. Wang, B.; Venkataramanan, G.; Illindala, M. Operation and control of a dynamic voltage restorer using transformer coupled H-bridge converters. IEEE Trans. Power Electron. 2006, 21, 1053-1061. [CrossRef]

8. Murugan, N.S.S.; Nirmalkumar, A.; Vijayakumar, T. Implementation of H Bridge Inverter Based DVR using Atmel 89c2051. Int. J. Comput. Electr. Eng. 2009, 1, 443-448. [CrossRef]

9. Bhalerao, S.N.; Reddy, C.O. A Novel Dynamic Voltage Restorer with Cascaded H-Bridge Inverter. Int. J. Adv. Res. Electr. Electron. Instrum. Eng. 2017, 6, 6501-6510.

10. Jiang, F.; Cheng, S.; Tu, C.; Guo, Q.; Li, Q.; Chen, C. Optimum control scheme of output voltage based on cascaded H-bridge DVR. CSEE J. Power Energy Syst. 2020, 6, 249-258.

11. Sivarajan, K.N.; Nirmal, S.; Jasmin, E.A.; Jayanand, B. Power Quality Improvement of Distribution System Using DVR with H-bridge Topology and Differential Inverter Control. In Proceedings of the 2021 International Conference on Communication, Control and Information Sciences, Idukki, India, 16-18 June 2021; pp. 1-8.

12. Fang, X.P.; Qian, Z.M.; Peng, F.Z. Single-phase Z-source PWM AC-AC Converters. IEEE Trans. Power Electron. 2005, 3, 121-124.

13. Usha, R.P.; Rajkumar, M.; Reddy, S.R. Voltage Sag/Swell Compensation Using Z-source Inverter Based Voltage Restorer. In Proceedings of the 2011 International Conference on Emerging Trends in Electrical and Computer Technology, Nagercoil, India, 23-24 March 2011; pp. 268-273.

14. Hossein, S.H.; Sedaghati, F.; Sarhangzadeh, M. Compensation of Voltage Sags and Swells Using Z-source AC-AC Converter. In Proceedings of the 2009 International Conference on Electrical and Electronics Engineering, Bursa, Turkey, 5-8 November 2009; pp. 1611-1612.

15. Kumar, B.V.; Bhatia, R.S.; Nijhawan, P. Power quality enhancement using SVPWM Z-source inverter based DVR. In Proceedings of the 7th India International Conference on Power Electronics, Patiala, India, 17-19 November 2016; pp. 1-6. 
16. Trabelsi, M.; Kakosimos, P.; Komurcugil, H. Mitigation of grid voltage disturbances using quasi-Z-source based dynamic voltage restorer. In Proceedings of the IEEE 12th International Conference on Compatibility, Power Electronics and Power Engineering (CPE-POWERENG 2018), Doha, Qatar, 10-12 April 2018; pp. 1-6.

17. Tu, C.; Hunan University; Guo, Q.; Jiang, F.; Chen, C.; Li, X.; Xiao, F.; Gao, J. Dynamic voltage restorer with an improved strategy to voltage sag compensation and energy self-recovery. CPSS Trans. Power Electron. Appl. 2019, 4, 219-229. [CrossRef] 